Hot seat
Animal researchers
seek government help
against protesters
p443

\title{
Agencies face uphill battle to keep United States free of BSE
}

Meredith Wadman, Washington

US government agencies are confronting a tough test of their much-vaunted ability to maintain a safe food supply, as they scramble to block possible paths for the entry of mad cow disease into the United States. Their latest action is to extend a ban on blood donors from European countries.

Until late last year the disease, more properly known as bovine spongiform encephalopathy (BSE), was thought to be largely confined to the United Kingdom, Switzerland and Ireland. In the United Kingdom, more than 80 people have died from variant Creutzfeldt-Jakob disease (vCJD), an analogous human disease presumed to be contracted by eating infected cattle.

But the BSE panic is fanning out across Europe, with Italy the latest country to succumb (see below). Its implications are registering with the American public for the first time, putting intense pressure on agencies charged with protecting food safety. These, primarily the Food and Drug Administration (FDA) and the United States Department of Agriculture (USDA), confront a challenge that is logistically complex, politically delicate and scientifically uncertain.

"The FDA and USDA face a tough balancing act against a frightening, little-known enemy. It's as tough as any [challenge] in the last decade," says Arthur Caplan, director of the University of Pennsylvania's Center for Bioethics. He chairs a committee that advises the Department of Health and Human Services, the FDA's parent agency, on blood safety.

An FDA advisory committee last week recommended extending a ban on blood donors to include people who have, since 1980, spent ten years in France, Portugal or the Republic of Ireland. Previously, the 1999 ban had applied only to those who had spent six months or more in the United Kingdom between 1980 and 1996.

It is not known whether the disease can be spread through blood transfusion, although the epidemiological evidence so far makes this unlikely. But, says Paul Brown, chair of the advisory committee and director of the Laboratory of Central Nervous System Studies at the National Institute of Neurological

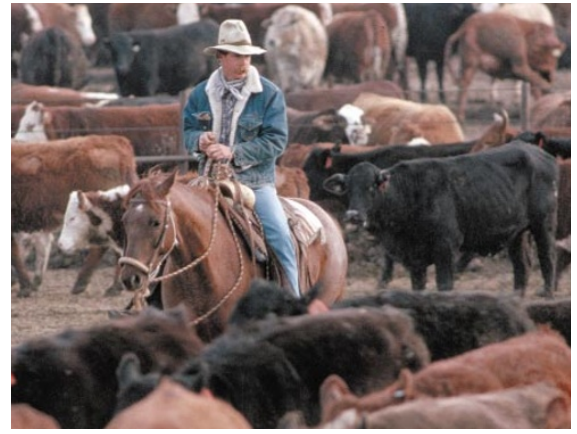

Cowed: BSE could unseat the US cattle industry.

Disorders and Stroke, "the committee chose a compromise conservative position. They are assuming there's a significant potential risk of exposure in Europe."

The committee had been pressed unsuccessfully by the US Red Cross and others to bar donors who had spent less than six months in the United Kingdom and to extend the ban to the whole of Europe.

BSE and vCJD are caused by abnormally shaped brain proteins or prions. These cause neurological deterioration, leading to dementia, uncontrolled movement and rapid death. There is no diagnostic test for the diseases, which are confirmed by microscopic examination of the brain after death.

No cases of BSE or vCJD have been diagnosed in the United States, according to the USDA and the Centers for Disease Control and Prevention. The USDA has examined the brains of 11,900 cattle in the past decade.

"Currently we are free of mad cow disease in cows and variant CJD in humans. Every possible effort must be expended to keep us in that category," says Sidney Wolfe, who heads the consumer watchdog Public Citizen Health Research Group in Washington DC.

Regulation of the many routes by which BSE might enter the United States is complex. The FDA monitors animal feed, blood products, vaccines and dietary supplements. The USDA is responsible for safety of meat and the health of 900 million US cattle.

"If we get BSE in this country, our cattle industry goes down the tubes," says Jim Rogers, a spokesman for the USDA's Animal and Plant Health Inspection Service.

The FDA has no power to stop the manufacturers of dietary supplements using processed cow parts, including brain, in

\section{Italians drop beef as first cow tests positive}

Sergio Pistoi, Turin

Italy's demand for beef has collapsed dramatically following last week's discovery of the country's first BSE case. The finding came two weeks after the government introduced tests for all cattle over 30 months old.

Butchers reported a much sharper fall in demand than the estimated $30 \%$ decrease that followed the BSE crisis in France last October (see Nature 408, 392; 2000). One association of butchers said that consumption fell by $70-90 \%$ in the days after the discovery.

The infected animal was a six- year-old cow from a farm near Brescia in northern Italy. It had shown no symptoms of BSE but was found to be positive in a prionics test performed on brain tissue. The initial result was confirmed by researchers at Italy's national BSE reference centre in Turin.

To ease the pressure on laboratories that are now running as many as 1,500 tests a day, the government is encouraging farmers to slaughter older animals without testing. Only ten veterinary centres in the country are equipped for rapid testing, but Umberto Veronesi, the health minister, said that 13 more will be established in the next few weeks.

The government is also working to computerize a national bovine register, which currently covers about four-fifths of the cattle herd, to track each animal's origin and history. The testing age is also to be lowered to 24 months, in accordance with a European Union directive.

According to Veronesi, only one of 6,000 tests performed by the end of last week was found positive, indicating that the rate of infection is low. But he said 50,000 tests were needed to get a reliable estimate of the rate. 
their products. Similarly, a USDA import ban on bovine tissues applies only if they are destined for use in food and medical products, not if they are to become dietary supplements. One nationally distributed supplement lists 17 bovine organs, including brain, as ingredients.

The United States has not imported British beef since 1985, and it banned imports of live cows from BSE-affected countries in 1989. But a recent report by a scientific advisory panel to the European Union says that tonnes of high-risk European beef products are shipped to the United States annually. They include gelatin, collagen, semen and albumin, and are used in products including cosmetics and vaccines. (In December, the FDA forbade US drug-makers to use bovine serum from BSE-affected countries in certain vaccines, but vaccines produced before the ban are still in use.)

Besides the loopholes for exports, measures to protect the US herd are sometimes disregarded. BSE is believed to have spread through the practice, now prohibited, of using cow and sheep parts in cattle feed. The FDA announced on 10 January that hundreds of US feed producers are not complying with 1997 regulations enforcing the ban.

Beyond the challenge of enforcing current regulations, the US agencies need to examine how to plug loopholes, and to determine the best way to spend limited resources fighting a dimly understood enemy. How much effort should be spent in developing a screening test for the diseases or finding a treatment, or on blocking any imported or home-grown vehicle that might spread the diseases?

Deer and elk herds in the western United States, for instance, are being afflicted in growing numbers with an analogous ailment called chronic wasting disease. Last week, the committee that extended the blood-donor ban was asked to consider if and how blood donations from people exposed to these deer and elk should be restricted. It decided there were not yet enough data to implement restrictions on them.

All of these issues "get into foreign policy questions, trade issues, regulation of hunters, which Americans hate. These are all politically tricky," says Caplan.

At the advisory committee meeting last week, scientists complained of the lack of data on which to base their decisions - including the future curve of the epidemic in Europe, and the risk of exposure in other European countries compared with the United Kingdom. "These decisions ... are really guesses," said Stanley Prusiner, who won a Nobel prize in 1997 for discovering prions and elucidating how they cause disease.

\section{Public have right to see data from all gene trials, says FDA}

Paul Smaglik, Washington

The US Food and Drug Administration (FDA) last week put forward proposals to make clinical trials in gene therapy and xenotransplantation more transparent. The move drew support from some academic scientists, but criticism from the biotechnology industry.

The proposal - which interested parties have 90 days to comment on - would close a loophole that allows some data from privately funded trials to be concealed. Comments can be sent to fdadockets@oc.fda.gov.

Public disclosure became an issue in 1999, after a teenager died in a clinical trial at the University of Pennsylvania.

Adverse effects from federally funded gene-therapy trials are meant to be reported to the National Institutes of Health (NIH) and the FDA. But after the death, NIH investigators learnt that hundreds of such events had not been reported to the agency, which makes data public through the Recombinant DNA Advisory Committee (RAC). Most had only been reported to the FDA, which keeps them confidential. Researchers complained that the agencies had different reporting standards. Last week's announcement aims to harmonize those requirements, and expand them to xenotransplantation.

The new policy would ensure that data on adverse events from all gene-therapy trials would be made public. Some are already made public through an NIH database: the change would ensure that this database contains information from all ongoing trials.

Inder Verma, president of the American Society of Gene Therapy, applauds the FDA's proposal, describing it as necessary to regain public trust. "Anything that will make it a more open process is good," says Verma, a Salk Institute gene therapy researcher.

Michael Werner of the Biotechnology Industry Organization (BIO), which opposes the proposal, says it raises privacy concerns. The BIO favours releasing aggregated safety data and reports on trends in adverse events rather than information about individual trials.

| http://www4.od.nih.gov/oba/clinicaltrial.htm

\section{Students fuzzy about the future}

\section{Mark Schrope}

Students at US graduate schools are happy to be doing PhDs and love their research, a new survey says. But they do not get enough teacher training or career advice, and their rapport with staff has room for improvement.

Just 3\% of those surveyed admitted to being unhappy with their decision to pursue a $\mathrm{PhD}$ and $93 \%$ said their research interested them "a great deal". But more than a third might consider changing universities, advisers or dissertation topics

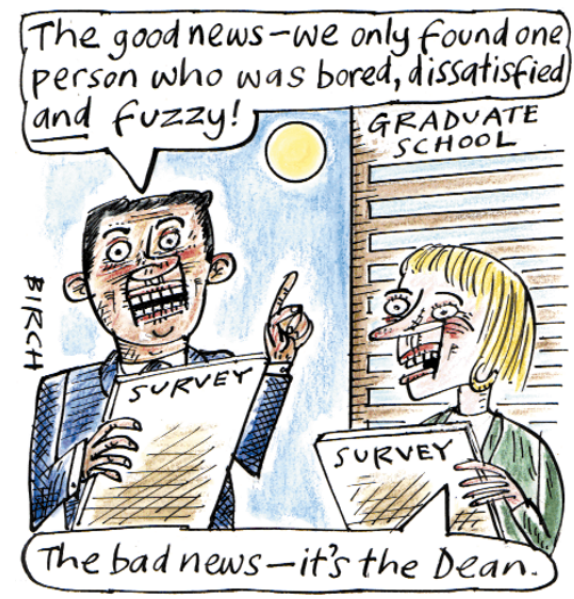

if given the chance to start again.

The survey, carried out by the University of Wisconsin at Madison for the Pew Charitable Trusts, polled more than 4,000 students in the third year or above in 27 graduate programmes.

"We were trying to bring the experiences and voices of students into the debate," says lead author, educationalist Chris Golde.

Only about a third felt their programmes were preparing them to teach lecture courses, compared with three-quarters who felt up to the task of conducting research. Students in the 'hard sciences' were more likely than those in the social sciences or humanities to be required to teach, but were less likely to receive any training.

Under half had a clear understanding of what (or how long) it would take for them to graduate. Molecular biologists and chemists were the fuzziest on these points, probably reflecting the unpredictable nature of laboratory research, according to the report.

The report's authors call for better communication between staff and students, including annual reviews to discuss needs, expectations and progress - an opportunity now only available to about half the students. They also urge students to voice their needs and expectations. 